\title{
Factors associated with dengue fever outbreak in Dire Dawa administration city, October, 2015, Ethiopia - case control study
}

\author{
Luna Habtamu Degife ${ }^{*^{*}}$ D, Yoseph Worku², Desalegn Belay ${ }^{1}$, Abyot Bekele ${ }^{1}$ and Zegeye Hailemariam³
}

\begin{abstract}
Background: Dengue Fever (DF) is underrecognized mosquito borne viral disease prevalent in tropical and subtropical regions. In 2013, Ethiopia reported the first confirmed DF outbreak in Dire Dawa city which affected 11, 409 people. During the outbreak investigation, we determined factors associated with DF and implemented control measures.

Methods: We conducted a 1:2 un-matched case control study from October 7-15/2015. Case was any person with fever of 2-7 days and more than two symptoms: headache, arthralgia, myalgia, rash, or bleeding from any part of the body. We recruited participants using purposive sampling from health facilities and used structured questionnaire to collect data. Multiple logistic regression analysis was conducted to control confounders and to identify factors associated with DF. Sixty-nine serum-samples were tested by Enzyme-Linked Immunosorbent Assay (ELISA).

Results: We enrolled 210 participants (70 cases and 140 controls) in the study. Females accounted for 51.4\% of cases and $57.1 \%$ of controls. The mean age was $23.7 \pm 9.5$ standard deviation (SD) for cases and $31.2 \pm 13$ SD for controls. Close contact with DF patient (Adjusted odds ratio $[A O R]=5.36,95 \%$ confidence interval [Cl]: 2.75-10.44), nonuse of bed-nets ( $A O R=2.74,95 \% \mathrm{Cl}: 1.06-7.08)$ and stagnant water around the village ( $\mathrm{AOR}=3.61,95 \% \mathrm{Cl}: 1.31-9.93)$ were independent risk factors. From the samples tested, 42 were confirmed positive.

Conclusions: Individuals who live with DF patient, around stagnant water and do not use bed nets are at high risk of contracting the disease. Health education on DF prevention was given and mosquito breeding sites were drained. Strong vector prevention strategies are recommended by enhancing the existing malaria prevention and control program.
\end{abstract}

Keywords: Dengue fever, Dire Dawa, Outbreak, Risk factors

\section{Background}

Classic dengue fever (DF), or "break bone fever," is the most rapidly spreading arboviral disease with the highest prevalence in the tropical and subtropical regions of the world [1]. The virus belongs to the genus Flavivirus, family Flaviviridae with 4 serotypes known as dengue virus type 1, 2, 3 and 4. [2]. DF including the severe forms, dengue hemorrhagic fever (DHF) and dengue shock syndrome (DSS) can be caused by any of the serotypes. A person infected with one serotype is likely

\footnotetext{
* Correspondence: lunahabt@gmail.com

${ }^{1}$ Center for Public Health Emergency Management, Ethiopian Public Health Institute, PO.BOX: 1242, Addis Ababa, Ethiopia

Full list of author information is available at the end of the article
}

to develop DHF if later on infected with a different serotype but protected for the similar serotype [3]. It is characterized by acute onset of high fever 3-14 days after the bite of an infected female Aedes aegypti, a domestic day-biting mosquito. Even though most Dengue infections are asymptomatic or cause a relatively mild disease, some DF infections may result in severe and potentially life-threatening disease [4]. With early diagnosis and proper management, the case-fatality rate (CFR) of DHF is generally under $1 \%$, but the CFR may be over $10 \%$ once shock develops [5].

More than $50 \%$ of the world's population are at risk and over 125 countries are endemic to DF. The global incidence of DF has increased and expanded geographically 
by 30 folds from the past 50 years. Worldwide, it is estimated that 50 to 270 million dengue infections occur every year, out of which two million cases are severe DHF and 21,000 result in death [6,7]. Determinant factors of dengue global epidemiology trends include, but are not limited to: Demographic changes, increased urban population, modern transportation and changes in public health policies [6].

In Africa, laboratory diagnostics is not done for most of the febrile illnesses and is taken as malaria. Even though outbreaks of dengue have been reported, there is limited data on the incidence and prevalence of the disease. The first report of Dengue in Africa was in the late 19th and early 20th centuries from Burkina Faso, Zanzibar, Senegal, Egypt and South Africa [8].

Despite the little documented data in Africa, the disease is endemic to 34 countries with all four dengue virus serotypes in circulation. Available data suggest that Aedes aegypti mosquitoes are known to be present in all but five countries [9]. In Ethiopia, DF was diagnosed only among travelers returning to countries to which dengue was not endemic but never reported as an outbreak locally [8] till September 2013, when the first major outbreak occurred in Diredawa administration city with a total of 11,409 cases [10]. Therefore, the aim of this study is to determine factors associated with DF outbreak in Diredawa administration city in 2015.

\section{Objective}

To determine the risk factors associated with Dengue Fever in Diredawa administration city, October 2015.

\section{Methods}

Dire Dawa administration city is found 515 Kilometers south east of Addis Ababa, the capital of Ethiopia. The council has a total approximate population of 400,000 and nine operational districts (4 rural and 5 urban districts). It is further classified into 10 urban and 37 rural kebeles, the smallest administrative unit in Ethiopia. About $70 \%$ of the people live in the city while the rest are in the surrounding rural kebeles. Moreover, the council has 2 government owned Hospitals, 15 health centers and 31 health posts. Additionally, there are 3 private hospitals and 21 private clinics. There are both arid and semiarid climatic zones in the council. The north eastern part of the city is relatively sparsely populated lowland exhibiting agro-pastoral and pastoral system, and the southeastern part uses mixed farming system. The city lies between 1000 to $2000 \mathrm{~m}$ above sea level with an average monthly temperature of $24.8{ }^{\circ} \mathrm{C}$ and annual rainfall of $604 \mathrm{~mm}[10,11]$. The warm climate of the City is favorable for the transmission of vector borne diseases like malaria and DF.
An unmatched case-control study design was used to investigate the outbreak. All residents of Diredawa Administration city were the source population. Cases were either confirmed or epidemiologically linked Dengue Fever cases while Controls were all people without Suspected DF symptoms. Additionally, confirmed cases were suspected cases with laboratory confirmation (positive IgM antibody, rise in IgG antibody titers, positive PCR or viral isolation). Moreover, epidemiologically linked cases were suspected cases presented at the location of ongoing outbreak within previous two weeks of onset of an acute febrile illness or dengue, or association in time and place (e.g., household member, family member, classmate, or neighbor) with a confirmed or probable dengue case.

All confirmed or epidemiologically linked cases of Dengue fever found in Health facilities from October 7 to 15, 2015 were included in the study. For the Controls, resident of Diredawa Town who was a neighbor to a case and who did not develop signs and symptoms of DF were included. On the other hand, Suspected Dengue fever patients who were critically ill and controls who were not a permanent resident of Diredawa city were excluded from the study. This study was carried out from October 7 to 15, 2015 at various private and public hospitals including health centers and private clinics of Diredawa. Health facilities were selected based on case load and all confirmed and epidemiologically linked cases at the health facilities during the investigation period were enrolled. Approval of the health facilities administration was obtained before approaching the patients. A total of 70 cases were interviewed with a ratio of 1:2 making the controls 140. Controls were neighbors of cases. After each case was interviewed at the hospital, their houses were visited and neighbors were interviewed.

The data was collected through face to face interview using structured questionnaire initially prepared in English and then translated to Amharic (Additional file 1). The questionnaire was divided in to three main areas covering demographic variables, risk factors associated with Dengue fever and Knowledge regarding the disease. For verifying consistency, a pre-tested questionnaire was used.

Sixty-nine serum samples were collected from malaria negative suspected patients by skilled professional and sent to Ethiopian Public Health Institute (EPHI) national laboratory. Samples were collected to identify the cause of the outbreak. The outbreak was confirmed first by RDT and then RT-PCR was performed for confirmation.

The data was checked for completeness and consistency and analyzed using SPSS version 20 software. Associations between factors and Dengue Fever 
status were tested first by the chi-square test and for cells with values less than 5, Fisher's exact test was applied. In order to investigate relative importance of the variables in relation to the dependent factor and any confounding between them, they were fitted in a binary logistic regression model to identify independent factors. Those variables that come significant in the bivariate analysis were fitted to a multivariable analysis followed by a backward stepwise procedure to control confounding. Results were displayed using texts, tables and graphs and statistical significance was interpreted using Odd ratio with $95 \%$ confidence interval and $P$ value $<0.05$.

Ethical clearance was obtained from EPHI. A letter was written for the regional health bureau in order to obtain approval on the data collection. An informed consent was obtained from all study participants. Where the age was less than 16 years, assent was obtained from the children/adolescents and permission was obtained from respective parents/guardians. Confidentiality of information was assured and ensured. Participants were treated with respect and willingly participated in the study with no payment or coercion.

\section{Results}

Socio demographic characteristics

A total of 210 individuals (70 cases and 140 controls) were approached for interview. Response rate of the study was $100 \%$, no decline of participant in the study individuals. From the total respondents, 94 were males and 116 were females. Out of the 70 cases, 34(48.6\%) were males. The mean age for cases was $23.7 \pm 9.5 \mathrm{SD}$ and for controls $31.2 \pm 13$ SD. From the total cases, 39(55.7\%) were singles and $31(44.3 \%)$ were married. Among the cases, more than half $39(55.7 \%)$ did not have occupation whereas, among the controls, those who work privately and those who do not have occupation were equal, 60(42.9\%). Half of the cases $35(50 \%)$ have finished secondary school and only $16(23 \%)$ of them have managed to finish college or university. While for the controls 56(40\%) have finished secondary school whereas, 20(14.3\%) and 21(15\%) were illiterate and reached college or university respectively (Table 1 ).

Table 1 Demographic characteristics of DF Cases and Controls, Diredawa city, October 2015

\begin{tabular}{|c|c|c|c|c|c|}
\hline Characteristics & Cases $n=70$ & Controls $n=140$ & Total $n=210$ & $P$-Value & COR $(95 \% \mathrm{Cl})$ \\
\hline \multicolumn{6}{|l|}{ Sex } \\
\hline Male & $34(48.6 \%)$ & $60(42.9 \%)$ & $94(44.8 \%)$ & & \\
\hline Female & $36(51.4 \%)$ & $80(57.1 \%)$ & $116(55.2 \%)$ & 0.433 & $1.259(0.708-2.240)$ \\
\hline \multicolumn{6}{|l|}{ Age group } \\
\hline$<5$ & $2(2.9 \%)$ & $0(0 \%)$ & $2(0.95 \%)$ & & \\
\hline $5-14$ & $9(12.9 \%)$ & $7(5.0 \%)$ & $16(7.6 \%)$ & & \\
\hline $15-44$ & 57 (81.4\%) & $113(66.5 \%)$ & $170(81.0 \%)$ & & \\
\hline$>45$ & $2(2.9 \%)$ & $20(14.3 \%)$ & $22(10.4 \%)$ & 0.033 & $5.044(1.139-22.337)$ \\
\hline \multicolumn{6}{|l|}{ Marital Status } \\
\hline Single & $39(55.7 \%)$ & $69(49.3 \%)$ & $108(51.4 \%)$ & & \\
\hline Married & $31(44.3 \%)$ & $71(50.7 \%)$ & $102(48.6 \%)$ & 0.380 & $1.295(0.727-2.304)$ \\
\hline \multicolumn{6}{|l|}{ Occupation } \\
\hline No Occupation & $39(55.7 \%)$ & $60(42.9 \%)$ & $99(47.1 \%)$ & & \\
\hline Private Business & $20(28.6 \%)$ & $60(42.9 \%)$ & $80(38.1 \%)$ & & \\
\hline Government Employee & $11(15.7 \%)$ & $20(14.3 \%)$ & 31 (14.8\%) & 0.272 & $0.606(0.248-1.480)$ \\
\hline \multicolumn{6}{|l|}{ Education } \\
\hline Illiterate & $6(8.6 \%)$ & $20(14.3 \%)$ & $26(12.4 \%)$ & & \\
\hline Primary & $13(18.6 \%)$ & $43(30.7 \%)$ & $56(26.7 \%)$ & & \\
\hline Secondary & 35 (50\%) & $56(40 \%)$ & $91(43.3 \%)$ & & \\
\hline Tertiary & $16(22.9 \%)$ & $21(15 \%)$ & $37(17.6 \%)$ & 0.617 & $0.820(0.378-1.781)$ \\
\hline \multicolumn{6}{|l|}{ Ethnicity } \\
\hline Amhara & $34(48.6 \%)$ & $50(35.7 \%)$ & $84(40 \%)$ & & \\
\hline Oromo & $22(31.4 \%)$ & $45(32.1 \%)$ & 67 (31.9\%) & & \\
\hline Somali & $8(11.4 \%)$ & 27 (19.3\%) & $35(16.7 \%)$ & & \\
\hline Others & $6(8.6 \%)$ & $18(12.9)$ & $24(11.4 \%)$ & 0.477 & $1.467(0.511-4.213)$ \\
\hline
\end{tabular}

The numbers in Bold reflect significant variables with $P$ value $<0.05$ 


\section{Laboratory result}

First 69 samples were analyzed by RDT at the field. Of which 26 were positive and the rest were negative. However, for further confirmation RT-PCR (Real time reverse transcription polymerase chain reaction) was done and 42 were confirmed positive, 20 were negative and 7 samples were not applicable (samples were inadequate). The rest of the cases were epidemiologically linked by person, place and time with the cases.

\section{Knowledge towards dengue fever}

The interviewees were also asked knowledge questions regarding DF and out of the total cases, $34.2 \%$ of them heard about DF, while the rest $44.3 \%$ of the controls had a clue about the disease. Only $11.4 \%$ of the cases and $7.1 \%$ of the controls stated virus as the cause for DF. On the other hand, $27.1 \%$ of the cases and $26.4 \%$ of the controls knew the mode of transmission. Moreover, $90 \%$ of the cases and $91 \%$ of the controls had no idea regarding the time mosquito bites. Additionally, respondents were asked about the prevention of the disease and it was found that $75.7 \%$ of the cases and $73.6 \%$ of the controls were unaware of it. Even though more than half of the respondents didn't hear about Dengue, almost 27\% of the cases knew the symptoms (Table 2).

\section{Risk factors towards dengue fever}

From the total cases only $2.9 \%$ had previous exposure to the disease. The availability and use of LongLastingInsecticidal Nets (LLINs) were assessed and it was found that $20 \%$ of the cases have LLINS while $37.9 \%$ of the controls had access to LLINs. Only $10 \%$ of the cases and $23.6 \%$ of the controls use it while sleeping. Though almost all respondents had water holding containers in their houses, there were no larvae identified in the households. Thirty-nine and $36 \%$ of the cases stay at their home in the morning and afternoon respectively. While for controls, 33 and $37 \%$ are at home during the respective times. In addition to this, $18.6 \%$ of the cases were exposed to stagnant water around their house of which $80 \%$ of them living at a distance of $<100 \mathrm{~m}$ from the stagnant water. Moreover, none of the respondents' house was sprayed in the last three months. In terms of close contact, $57 \%$ of the cases had close contact with a person of the same complaint, while only $19 \%$ of the controls had similar exposure. None of the cases use repellant on their skins while $2.9 \%$ of the controls use. Additionally, 17.1 and $15.7 \%$ of the cases and controls respectively use repellant in their houses. Moreover $39.5 \%$ of the total participants use window screen. Since Diredawa's weather is warm, more than three quarter of the cases and controls (80\%) each wear short sleeve clothes (Table 3).

Availability and utilization of LLINs $(p=0.010$ and 0.022 respectively), availability of water holding container $(p=0.005)$, close contact with DF patient $(p=$ $0.000)$ and the availability of stagnant water around the house $(p=0.009)$ were important risk factors (Table 3$)$.

After backward logistic regression was performed, three variables remained significant: utilization of LLINs

Table 2 Knowledge on Dengue Fever cases and controls, Diredawa city, 2015

\begin{tabular}{|c|c|c|c|c|c|}
\hline Characteristics & Case $n=70$ & Control $n=140$ & Total $n=210$ & $P$-Value & COR $(95 \% \mathrm{CI})$ \\
\hline \multicolumn{6}{|c|}{ Heard About Dengue } \\
\hline Yes & $24(34.2 \%)$ & $62(44.3 \%)$ & $86(40.0 \%)$ & & \\
\hline No & $46(65.7 \%)$ & $78(55.7 \%)$ & $124(59.01 \%)$ & 0.166 & $1.524(0.840-2.764)$ \\
\hline \multicolumn{6}{|c|}{ Cause of Dengue } \\
\hline Know & $8(11.4 \%)$ & $10(7.1 \%)$ & $18(8.6 \%)$ & & \\
\hline Don't know & $62(88.6 \%)$ & $130(92.9 \%)$ & $192(91.4 \%)$ & 0.300 & $1.677(0.631-4.459)$ \\
\hline \multicolumn{6}{|c|}{ Mode of transmission } \\
\hline Know & $19(27.1 \%)$ & $37(26.4 \%)$ & $56(26.7 \%)$ & & \\
\hline Don't Know & $51(72.9 \%)$ & $103(73.6 \%)$ & $154(73.3 \%)$ & 0.912 & $1.037(0.543-1.981)$ \\
\hline \multicolumn{6}{|c|}{ Time Mosquito bites } \\
\hline Know & $7(10 \%)$ & $12(8.6 \%)$ & $19(9.0 \%)$ & & \\
\hline Don't Know & $63(90 \%)$ & $128(91.4 \%)$ & $191(90.9 \%)$ & 0.734 & $1.185(0.445-3.157)$ \\
\hline \multicolumn{6}{|c|}{ Water required for breeding } \\
\hline Know & $17(24.3 \%)$ & $37(26.4 \%)$ & $54(25.7 \%)$ & & \\
\hline Don't Know & $53(75.7 \%)$ & $103(73.6 \%)$ & $156(74.2 \%)$ & 0.738 & $0.893(0.460-1.733)$ \\
\hline \multicolumn{6}{|c|}{ Knew Symptoms } \\
\hline Yes & $19(27.1 \%)$ & $43(30.7)$ & $62(29.5 \%)$ & & \\
\hline No & 51 (72.9\%) & 97 (69.3\%) & 148 (70.5\%) & 0.593 & $0.840(0.444-1.590)$ \\
\hline
\end{tabular}


Table 3 Risk factors towards Dengue Fever cases and controls, Diredawa city, October 2015

\begin{tabular}{|c|c|c|c|c|c|}
\hline Characteristics & Cases $n=70$ & Controls $n=140$ & Total $n=210$ & $P$-Value & COR $(95 \% \mathrm{Cl})$ \\
\hline \multicolumn{6}{|c|}{ Infected Previously } \\
\hline Yes & $2(2.9 \%)$ & $6(4.3 \%)$ & $8(3.8 \%)$ & & \\
\hline No & $68(97.1 \%)$ & $134(95.7 \%)$ & $202(96.2 \%)$ & 0.613 & $1.522(0.299-7.744)$ \\
\hline \multicolumn{6}{|c|}{ Availability of LLINS } \\
\hline Yes & $14(20 \%)$ & $53(37.9 \%)$ & 67 (32.0\%) & & \\
\hline No & $56(80 \%)$ & $87(62.1 \%)$ & $143(68.1 \%)$ & 0.010 & $2.437(1.237-4.800)$ \\
\hline \multicolumn{6}{|c|}{ Utilization of LLINs } \\
\hline Yes & $7(10 \%)$ & $33(23.6 \%)$ & 40 (19.0\%) & & \\
\hline No & $63(90 \%)$ & $107(76.4 \%)$ & $170(81.0 \%)$ & 0.022 & $2.776(1.159-6.645)$ \\
\hline \multicolumn{6}{|c|}{ Water Holding Container } \\
\hline Yes & $56(80 \%)$ & $131(93.6 \%)$ & $187(89.0 \%)$ & & \\
\hline No & $14(20 \%)$ & $9(6.4 \%)$ & $23(11.0 \%)$ & 0.005 & $3.639(1.488-8.896)$ \\
\hline \multicolumn{6}{|c|}{ Stagnant water in the village } \\
\hline Yes & $13(18.6 \%)$ & $9(6.4 \%)$ & $22(10.5 \%)$ & & \\
\hline No & $57(81.4 \%)$ & $131(93.6 \%)$ & $188(89.5 \%)$ & 0.009 & $0.301(0.122-0.745)$ \\
\hline \multicolumn{6}{|c|}{ close contact in the last 2 weeks } \\
\hline Yes & $40(57.1 \%)$ & $27(19.3 \%)$ & 67 (31.9\%) & & \\
\hline No & $30(42.9 \%)$ & $113(80.7 \%)$ & $143(68.1 \%)$ & 0.000 & $0.179(0.095-0.337)$ \\
\hline \multicolumn{6}{|c|}{ Remained at home in the morning from 8 to $10 \mathrm{am}$} \\
\hline Yes & $27(38.6 \%)$ & $46(32.9 \%)$ & $73(34.8 \%)$ & & \\
\hline No & $43(61.4 \%)$ & $94(67.1 \%)$ & $137(65.2 \%)$ & 0.413 & $0.779(0.429-1.415)$ \\
\hline \multicolumn{6}{|c|}{ Remained at home in the afternoon 4-6 pm } \\
\hline Yes & $25(35.7 \%)$ & 49 (35\%) & $74(35.2 \%)$ & & \\
\hline No & $45(64.3 \%)$ & $91(65 \%)$ & $136(64.8 \%)$ & 0.919 & $0.969(0.532-1.766)$ \\
\hline \multicolumn{6}{|c|}{ Use of mosquito repellant in the House } \\
\hline Yes & $12(17.1 \%)$ & $22(15.7 \%)$ & $34(16.2 \%)$ & & \\
\hline No & $58(82.9 \%)$ & $118(84.3 \%)$ & $176(83.8 \%)$ & 0.791 & $0.901(0.417-1.947)$ \\
\hline \multicolumn{6}{|c|}{ Use of mosquito repellant in the skin } \\
\hline Yes & $0(0 \%)$ & $4(2.9 \%)$ & $4(1.9 \%)$ & & \\
\hline No & $70(100 \%)$ & $136(97.1 \%)$ & 206 (98.1\%) & 0.304 & \\
\hline \multicolumn{6}{|l|}{ Type of cloths } \\
\hline Short sleeves & $56(80 \%)$ & 112 (80\%) & $168(80 \%)$ & & \\
\hline Long Sleeves & $14(20 \%)$ & $28(20 \%)$ & $42(20 \%)$ & 1.000 & $1.000(0.488-2.049)$ \\
\hline
\end{tabular}

(adjusted OR $=2.74: 95 \% \mathrm{CI}: 1.06-7.08$ ), availability of stagnant water (adjusted OR $=3.61$ : 95\% CI: 1.31-9.93) and close contact with DF patients (adjusted OR $=5.36$ : 95\% CI: 2.75-10.44) (Table 4).

\section{Discussion}

The study showed that the risk factors of DF in Diredawa administration city were the availability of stagnant water around the house, the non-use of LLINs and having close contact with Dengue Fever patient. Those who have stagnant water around their houses were 3.6 times more at risk to have the disease. In consistence to this, results of a case control study carried out in Vietnam identified that people living near stagnant water like ponds, lakes or open sewers had higher rates of morbidity [12]. The DF epidemic in Brazil was also associated with proximity to uncontrolled water ways and stagnant water in tanks, gutters and cans [13]. This may be due to the fact that, Aedes aegypti breeds on artificial and natural water containers almost in and around households, construction sites, factories, etc. [14].

The current study has also found a significant association between Dengue fever and close contact with DF patient. Having close contact with DF patient has a 5.4 
Table 4 Independent predictors of Dengue Fever, Dire Dawa, October 2015

\begin{tabular}{llll}
\hline Characteristics & P-Value & S. E & AOR (95\%Cl) \\
\hline Close contact & & \\
Yes & & $5.36(2.75-10.44)$ \\
No & 0.000 & 0.340 & 1.0 \\
Utilization of LLINs while sleeping & & \\
$\quad$ Yes & & 1.0 \\
No & 0.034 & 0.486 & $2.74(1.06-7.08)$ \\
Stagnant water in the village & & \\
Yes & & $3.61(1.31-9.93)$ \\
No & 0.017 & 0.509 & 1.0 \\
\hline
\end{tabular}

times risk in acquiring the disease. This may be because of the likely availability of Aedes aegypti breeding site around the sick person's living environment which will also be a risk factor for a person spending more time with the patient.

Additionally, there is an association found between the uses of LLINs and DF showing that people who do not use LLINs were 2.7 times more likely to get infected than those who use. Another study done in Angola has also found that Behavior associated with protection from DENV infection included having recently used mosquito avoidance strategies (such as applying mosquito repellent or sleeping under a bed net) were protective from the disease [15]. On the contrary, study in Zambia revealed that up to $21 \%$ of the respondents using insect trapping nets (ITNs) were more likely to be infected with Dengue fever. This may be attributed to the fact that the mosquito Aedes aegypti commonly bites during the day and the use of ITNs while sleeping at nights would not be expected to provide a barrier between the humans and the vector unless it is used while sleeping during the day time [16].

The knowledge of the community regarding DF was also assessed and it was found that only $41 \%$ of the participants have heard about DF previously out of which $34 \%$ were cases. However, in a study conducted in Karachi, $96.5 \%$ of high socio-economic population and $88 \%$ of low socio-economic population have heard about the disease [17]. This discrepancy may be due to the recurrent occurrence of DF in Pakistan. Regarding the breeding site of the mosquito, only about a quarter of the cases had idea that water is required for the mosquito to breed. Whereas the study in Lahore [18] had showed that almost half of the patients knew stagnant water as a favorable breeding site. This difference may be due to the dengue awareness campaigns given in Lahore after the 2011 outbreak. Only 27\% of the cases could identify the vector as a mosquito, while in Lahore $72 \%$ of Dengue positive patients were aware that mosquito transmits the disease. Similarly, $97.3 \%$ of the participants in the study in Vietnam identified Aedes aegypti as the vector [19]. Regarding symptoms, 27\% of the patients knew the symptoms of DF, and this finding contradicts with the Lahore study, where $88 \%$ of the cases knew DF symptoms. The low awareness of the people about the disease may be due to the fact that the disease is not common in our country and mostly undetected.

Even though there was full response rate in this study, we interviewed only patients that appeared to health facilities and so may have missed factors related to cases that did not seek medical care. Moreover, controls were not willing to give blood samples and therefore it was not possible to confirm whether they were really free of the disease.

\section{Conclusions}

Presence of stagnant water around the house, not using LLINs while sleeping and having close contact with DF patient were independent risk factors for disease contraction.

In the absence of vaccination and effective drugs, the only intervention is vector control to contain the outbreak and prevent future occurrences. Therefore, draining of stagnant water, giving health education in LLINs use and early medical seeking for persons living with DF patients is needed. The vector control activity needs to be part of long-term control of DF that will also contribute to controlling other diseases with the same determinants.

\section{Additional file}

Additional file 1: Questionnaire - Dengue Fever outbreak. Factors associated with Dengue Fever Outbreak-Dire Dawa administration city, October 2015. (DOC 173 kb)

\section{Abbreviations}

AFENET: African field epidemiology network; AOR: Adjusted odds ratio; CDC: Center for disease control and prevention; CFR: Case fatality rate; COR: Crude odds ratio; DF: Dengue fever; DHF: Dengue hemorrhagic fever; DSS: Dengue shock syndrome; ELISA: Enzyme linked immune sorbent assay; EPHI: Ethiopian Public Health Institute; IRS: Indoor residual spray; LLINs: Long Lasting Insecticidal Nets; OPDs: Outpatient Departments; RDT: Rapid diagnostic test; RT-PCR: Real time polymerase chain reaction; SPSS: Statistical package for social sciences; WHO: World Health Organization

\section{Acknowledgments}

First of all, I would like to forward my sincere gratitude for my advisors: Yoseph Worku (MD, MPH) and Zegeye Hailemariam (DVM, MPH) for their kind and constructive inputs. Secondly, I would like to thank the Diredawa regional health bureau and health facilities in Diredawa for their cooperativeness and willing assistance during the investigation. Thirdly, my appreciation goes to all the study participants for their patience and hospitality to provide epidemiological information and clinical specimens. 


\section{Authors' contributions}

LHD, the corresponding author, was the major contributor in preparing the manuscript. YW supported in the analysis and interpretation of the data and revised the manuscript critically for important intellectual contents. DB performed the laboratory test including the analysis and interpretation of the laboratory data. Additionally, contributed a lot in the drafting and revising the manuscript. ZH contributed substantially in the design of the study and critical revision of the final approval of the manuscript to be published. $A B$ contributed a lot in the conception, revision and approval of the final version of the manuscript. All the authors agreed to be accountable for all aspects of the work in ensuring that questions related to the accuracy or integrity of any part of the work are appropriately investigated and resolved. All authors have approved the final manuscript.

\section{Funding}

Ethiopian Public Health Institute was the funding organization. As a national public health institute, it is the mandate of the Ethiopian Public Health Institute to investigate and respond to any outbreaks in the country. The study was done by the initiation of the institute to respond to the outbreak. The data collectors and investigators were also assigned by the institute. $A B$, who contributed a lot in the conception, revision and approval of the final version of the manuscript was the coordinator at the institute.

\section{Availability of data and materials}

The datasets used and/or analyzed during the current study are available from the corresponding author on reasonable request.

\section{Ethics approval and consent to participate}

Ethical clearance was obtained from Ethiopian Public Health Institute. A letter was written for Diredawa regional health bureau in order to obtain approval on the data collection. An informed written consent was obtained from all study participants. Where the age was less than 16 years, informed written consent was obtained from respective parents/guardians. Confidentiality of information was assured and ensured. Participants were treated with respect and willingly participated in the study with no payment or cohesion.

\section{Consent for publication}

Not applicable.

\section{Competing interests}

The authors declare that they have no competing interests.

\section{Author details}

${ }^{1}$ Center for Public Health Emergency Management, Ethiopian Public Health Institute, PO.BOX: 1242, Addis Ababa, Ethiopia. ${ }^{2}$ Saint Paul's Hospital Millennium Medical College, Addis Ababa, Ethiopia. ${ }^{3}$ Ethiopian Field Epidemiology and Laboratory Training Program, Addis Ababa, Ethiopia.

Received: 22 June 2018 Accepted: 20 May 2019

Published online: 28 May 2019

\section{References}

1. Soumyajit B, Gautam A, Goutam K. Pupal productivity of dengue vectors in Kolkata, India: implications for vector management. Indian J Med Res. 2013; 137(3):549-59.

2. Wininger DA, Fass RJ. Antibiotic cement and beads for orthopedic infections. Antimicrob Agents Chemother. 1996;40(12):2675-9.

3. Siqueira JB, Martelli CM, Maciel IJ, Oliveira RM, Ribeiro MG, et al. Household survey of dengue infection in Central Brazil: spatial point pattern analysis and risk factors assessment. Am J Trop Med Hyg. 2004;71(5):646-51.

4. Khormi HM, Kumar L. Modelling dengue fever risk based on socioeconomic parameters, nationality and age groups: GIS and remote sensing based case study. Sci Total Environ. 2011;409(22):4713-9.

5. Rigau-Perez JG, Vorndam AV, Clark GG. The dengue and dengue hemorrhagic fever epidemic in Puerto Rico. Am Soc Trop Med Hyg. 2001; 64(1, 2):67-74

6. World Health Organization. Dengue guideline for diagnosis, treatment, prevention and control. New Editio. Geneva: WHO and tropical disease research; 2009.

7. Ferreira GLC. Global dengue epidemiology trends. Rev Inst Med Trop. 2012; 54(18):55-6.
8. Amarasinghe A, Kuritsky JN, Letson GW, Margolis HS. Dengue virus infection in Africa. Emerg Infect Dis. 2011:17(8):1349-54.

9. Fred W. The dengue situation in Africa. Paediatr Int Child Health. 2012;32(1): $18-21$.

10. Abyot B, Mesfin M, Wubayehu K, Esayas K, Million W, et al. The first acute febrile illness investigation associated with dengue fever in Ethiopia, 2013: a descriptive analysis. Ethiop J Health Dev. 2014;28(3).

11. Ethiopian Government Portal. The Dire Dawa administrative council. Ethiopian Government Portal. 2012 [cited 2016 Jan 9]; Available at: URL: http://www.ethiopia.gov.et/dire-dawa-city-administration.

12. Toan DT, Hoat LN, Wright WH, Martens P. Risk factors associated with an outbreak of dengue fever/dengue hemorrhagic fever in Hanoi, Vietnam. Epidemiol Infect. 2014:1-5.

13. Heukelbach J, Araújo F, Oliveira SD, Sansigolo LR, Feldmeier H. Risk factors associated with an outbreak of dengue fever in favela in Fortaleza northEast Brazil. Trop Med Int Health. 2001;6(8):635-64.

14. CDC. Dengue and the Aedes aegypti mosquito. http://www.cdc.gov/ dengue/resources/30Jan2012/aegyptifactsheet.pdf Accessed 6 Jan 2016.

15. Sharp TM, Moreira R, Soares MJ, Costa LM, Mann J, DeLorey M. Under recognition of dengue during 2013 epidemic in Luanda, Angola. Emerg Infect Dis. 2015;21(8):1311-4.

16. Liwewe ML, Siziya S, Monze M, Ndumba IM, Masaninga F, et al. First serolprevalence of dengue fever specific immunoglobulin $\mathrm{G}$ antibodies in Western and North-Western provinces of Zambia. Virol J. 2014:11:135.

17. Syed M, Saleem T, Syeda UR, Habib M, Zahid R. Bashir a. et.al. Knowledge attitude and practices regarding dengue fever among adults of high and low socioeconomic groups. J Pak Med Assoc. 2010;60:243-7.

18. Zameer M, Shuja M, Ashraf A, Mukhtar N, Ahmad BM. Knowledge, Attitudes and practices study of dengue viral infection and its association with environmental factors and health issues, Lahore Pakistan. Afr J Environ Sci Technol. 2013;7(7):711-7.

19. http://www.ifrc.org/docs/Appeals/annual11/MAAVN001-Final-KAP-report-DFCC-0611.pdf. Accessed 25 Nov 2015.

\section{Publisher's Note}

Springer Nature remains neutral with regard to jurisdictional claims in published maps and institutional affiliations.
Ready to submit your research? Choose BMC and benefit from:

- fast, convenient online submission

- thorough peer review by experienced researchers in your field

- rapid publication on acceptance

- support for research data, including large and complex data types

- gold Open Access which fosters wider collaboration and increased citations

- maximum visibility for your research: over $100 \mathrm{M}$ website views per year

At BMC, research is always in progress.

Learn more biomedcentral.com/submission 